\title{
Reflexões sobre a Interinfluência entre Ciência e Política: O Caso da Homossexualidade
}

\author{
Aline Beckmann Menezes ${ }^{1}$ \\ Coordenação do Núcleo de Apoio Psicopedagógico das Faculdades Integradas Ipiranga, \\ Belém, PA, Brasil \\ Faculdade de Psicologia da Universidade Federal do Pará, Belém, PA, Brasil \\ Marcus Bentes de Carvalho Neto \\ Núcleo de Teoria e Pesquisa do Comportamento da Universidade Federal do Pará, \\ Belém, PA, Brasil
}

\begin{abstract}
Resumo
No século XXI vive-se um momento de conflitos ideológicos intensos acerca dos direitos civis de indivíduos homossexuais, os quais têm sido reiteradamente pautados em concepções e/ou dados supostamente científicos. O presente ensaio realiza uma reflexão sobre a interinfluência entre ciência e política, a partir do caso da investigação dos determinantes da orientação sexual. Para tal, foi apresentada uma discussão sobre a influência exercida por questões sócio-políticas sobre a pesquisa científica da orientação sexual. Em seguida, foram discutidos os usos políticos de dados científicos, em especial no que se refere aos determinantes da orientação sexual. A partir das reflexões feitas, este ensaio propõe que a luta por aquisição de direitos civis não deva ser dependente do avanço científico na identificação de determinantes da orientação sexual, mas, ao contrário, que a compreensão de que o comportamento humano é complexo e multideterminado seja suficiente para o respeito às múltiplas possibilidades de sua manifestação. Além disso, afirma que o respeito à diversidade não deve ser condicional à ausência de controle que é comumente inferida na determinação genética, mas as próprias noções de direitos, diversidade e controle requerem reflexão por parte da sociedade civil.
\end{abstract}

Palavras-chave: Orientação sexual, homossexualidade, ciência, determinação genética, política.

\section{Reflections about the Mutual Influence between Science and Politics: The Case of Homosexuality}

\begin{abstract}
At the XXI Century it is a moment of intense ideological conflicts about civil rights for homosexuals, which have been usually grounded upon supposed scientific data or conceptions. This essay reflects about the mutual influence between science and politic, through the case of the investigation of determinants of sexual orientation. To achieve that, it is presented a discussion regarding the influence of social and political issues involved in sexual orientation scientific research. Then the political use of scientific data is discussed, especially regarding the determinants of sexual orientation. Through the reflections presented, this essay propose that the struggle to obtain civil rights should not be relayed upon the
\end{abstract}

Endereço para correspondência: Faculdades Integradas Ipiranga, Núcleo de Apoio Psicopedagógico, Av. Almirante Barroso, 777, Marco, Belém, PA, Brasil 66000-000. Fone: (91) 3344-0700; Fax: (91) 3366-7100. E-mail: alinebcm@gmail.com e marcusbentesufpa@gmail.com

Agência de financiamento: Coordenação de Aperfeiçoamento de Pessoal de Nível Superior (CAPES). 
identification of sexual orientation determinants but, instead, the comprehension that human behavior is complex and multideterminated should be sufficient to defend respect to multiple forms of sexual manifestation. It states also that the respect to diversity should not be conditional to the absence of control that is inferred in the genetic determination, but the notion of right, diversity and control itself requires further reflection by the civil society.

Keywords: Sexual orientation, homosexuality, science, genetic determination, politics.

\section{Reflexiones sobre la Interacción entre la Ciencia y la Política: El Caso de la Homosexualidad}

\section{Resumen}

En el vigésimo primer siglo vive un momento de intenso conflicto ideológico sobre los derechos civiles de las personas homosexuales, que han sido guiados constantemente por los conceptos y/o datos supuestamente científicos. Esta prueba realiza una reflexión sobre la interacción entre la ciencia y la política, desde el caso de la investigación de los determinantes de la orientación sexual. Para ello, un análisis de la influencia ejercida por los temas socio-políticos sobre la investigación científica en la orientación sexual. Luego discutieron los usos políticos de los datos científicos, sobre todo en lo que respecta a los factores determinantes de la orientación sexual. A partir de las reflexiones, este ensayo propone que la lucha por la adquisición de los derechos civiles no debería depender de los avances científicos en la identificación de los determinantes de la orientación sexual, sino que el entendimiento de que el comportamiento humano es complejo y se multideterminada suficiente para respetar las múltiples posibilidades de su manifestación. Además, afirma que el respeto a la diversidad no debe estar condicionada a la ausencia de control que se infiere comúnmente en la determinación genética, pero las nociones de los derechos, la diversidad y el control requiere reflexión por parte de la sociedad civil.

Palabras clave: Orientación, homosexualidad, la ciencia, determinación genética, la política.

No século XXI vive-se um momento de conflitos ideológicos intensos acerca dos direitos civis de indivíduos homossexuais, os quais têm sido reiteradamente pautados em concepções e/ ou dados supostamente científicos. Recentemente, pôde-se observar no Brasil a repercussão na mídia de declarações feitas pelo pastor Silas Malafaia acerca da origem da homossexualidade, utilizando o argumento de que seria uma questão de escolha e não de determinação genética, de modo a não justificar a concessão de direitos civis (Mello, Amaral, \& Gabriela, 2013). Tais declarações foram feitas sob a alegação de fundamentação científica, o que resultou na manifestação do Conselho Federal de Psicologia (2013) e da Sociedade Brasileira de Genética (2013).

O episódio supramencionado foi apenas um de diversos conflitos envolvendo mídia, religião, política e ciência no que se refere ao tema da determinação da orientação sexual humana.
Emerge deste cenário um questionamento que na realidade deveria preceder tal discussão: de que forma o conhecimento científico pode ou deve ser utilizado no desenvolvimento de políticas públicas?

O presente ensaio realiza uma reflexão sobre a interinfluência entre ciência e política, a partir do caso da investigação dos determinantes da orientação sexual. Para tal, será inicialmente apresentada uma discussão sobre a influência exercida por questões sócio-políticas sobre a pesquisa científica da orientação sexual. Em seguida, serão discutidos os usos políticos de dados científicos, em especial no que se refere aos determinantes da orientação sexual. Espera-se poder contribuir para a atual discussão bem como a produção ética de conhecimento científico.

A discussão aqui apresentada será fundamentada principalmente em referências obtidas na produção da dissertação de mestrado da pri- 
meira autora (Menezes, 2005), tendo o levantamento bibliográfico sido atualizado para o presente artigo quando se demonstrou necessário para o debate aqui proposto.

\section{Influência Sócio-Política na Produção Científica sobre a Orientação Sexual}

A influência de questões políticas sobre a pesquisa científica de determinantes do comportamento é maior quando são abordados comportamentos considerados "polêmicos". A temática da homossexualidade se configura, antes de uma questão científica, uma questão política (ver, por exemplo, LeVay, 1996 e Trevisan, 1986/2002).

O comportamento homossexual tem sido objeto de estudos variados, enfatizando questões de saúde, etiológicas, terapêuticas, sociais, políticas, culturais, religiosas, econômicas. Dentre estas, uma das discussões mais polêmicas e que gera grandes repercussões sociais é aquela que aborda a etiologia do comportamento homossexual.

As primeiras pesquisas científicas sobre determinantes da homossexualidade remontam ao início do século XX, sendo focadas em diferenças anatômicas dos organismos de indivíduos homossexuais ou alterações hormonais, procurando identificar padrões diagnósticos (Dynes, 1987; Meyer-Bahlburg, 1977). Desde este período, pode-se observar que objetivos políticos se sobrepunham à formulação de um problema de pesquisa, afetando, inclusive, o impacto da divulgação dos dados (Burr, 1998). Assim, no princípio do século XX, a investigação da determinação da homossexualidade era pautada na perspectiva de diagnóstico e, consequentemente, de prevenção e/ou cura.

As primeiras referências a uma possível explicação endócrina da homossexualidade ocorreram na primeira década do século XX, a partir dos trabalhos de Eugen Steinach com transplantes de testículos de homens heterossexuais para homens homossexuais (LeVay, 1996). Esta tentativa de "cura" obteve muita repercussão na época, até ser condenada em função de questões éticas, ainda em meados da década de 20. As diversas pesquisas realizadas nesta época tinham como propósito a "conversão" à heterossexualidade, assim, iniciava-se a organoterapia (LeVay, 1996).

McGuire (1995) ressalta o cuidado a ser tomado ao estudar comportamentos polêmicos, destacando o quanto tais questões políticas devem afetar inclusive o rigor metodológico empregado na investigação científica, intensificando-o: 'O 'glamour' de trabalhar com comportamentos controversos não pode ser um substituto do rigor científico. Pesquisadores trabalhando com traços que são estigmatizados precisam ser ainda mais rigorosos com sua metodologia e extremamente cuidadosos com a generalização de seus dados" (McGuire, 1995, p. 141).

Contudo, muitas vezes tais cuidados não são observados. Discutindo este aspecto, Bancroft (1994) afirma que a importância da discussão moral e política que permeia o estudo de determinantes da orientação sexual é tão grande que faz com que a objetividade científica não tenha conseguido avançar no combate à repressão social com a mesma velocidade com a qual têm sido obtidos avanços tecnológicos e metodológicos (para uma diferença entre neutralidade e objetividade científicas, ver Dennett, 1997). Em uma argumentação similar, Paul (1993) sugere que os autores deveriam iniciar a descrição de seus trabalhos expondo os reais interesses subjacentes a eles. $\mathrm{O}$ contexto sócio-político vigente no período de desenvolvimento de cada linha de pesquisa precisaria, portanto, ser analisado com cuidado, em conjunto aos questionamentos metodológicos.

De Cecco e Parker (1995) apresentam uma revisão de publicações sobre a origem da homossexualidade a partir da repercussão que tiveram na mídia, sendo relatados em periódicos científicos de grande porte e discutidos em reportagens publicadas nos principais jornais e revistas dos Estados Unidos. Relatam que depois da grande repercussão sobre o trabalho de LeVay (1991) no qual o autor assumiu a homossexualidade, aumentando a atenção sobre o mesmo - vários autores procuraram justificar seus trabalhos a partir do efeito que a comprovação da determinação biológica teria sobre os direitos homossexuais.

As influências sócio-políticas sobre o estudo da origem da homossexualidade podem ser 
percebidas em várias etapas do processo investigativo. Desde a terminologia utilizada, os objetivos da pesquisa, o procedimento adotado e análise dos resultados precisam ser contextualizados para que possam ser compreendidos em sua plenitude.

Como pode ser observado na Tabela 1 , o próprio termo é afetado pelo significado que se pretendia dar, em cada momento histórico, ao comportamento sexual direcionado a indivíduos do mesmo sexo. Apesar das constantes alterações terminológicas, contudo, alguns destes termos foram adotados apenas em meios específicos (como homoerotismo, utilizado predominantemente em publicações psicoanalíticas e em alguns debates políticos no Brasil), enquanto outros não foram abandonados até os dias atuais (como pederastia, que é hoje sinônimo de relação homossexual tanto no meio jurídico quanto em dicionários, tal qual Ferreira, 2004).

O termo utilizado por uma determinada cultura não possui um caráter nominal de natureza meramente descritiva e sim é em si mesmo um posicionamento sócio-político, explícito ou im- plícito, sobre o próprio significado do comportamento homossexual. Hoje não há um consenso na utilização da terminologia, contudo, a seleção da palavra a ser empregada pode indicar qual é este posicionamento. $\mathrm{O}$ uso de termos que atribuem uma conotação biológica estrita ao fenômeno, por exemplo, remontam à luta por direitos sociais que se inicia no século XIX. Contudo, naquele período esta luta se desenvolve através da busca explícita da comprovação de uma base biológica para o fenômeno. Como afirma Foucault (1976/2006), o homossexual do século XIX era definido e reduzido à sua sexualidade, a qual estava atrelada à "morfologia, com uma anatomia indiscreta e, talvez, uma fisiologia misteriosa" (p. 50).

Já no século XX, a luta pelos direitos civis passou a se caracterizar pela defesa do prazer e pela concepção da orientação sexual como parte “imutável” do indivíduo (Trevisan, 1986/2002), o que também se refletiu na terminologia adotada. Um relato histórico sobre os movimentos sociais por grupos homossexuais no Brasil pode ser encontrado em Molina (2011).

Tabela 1

Síntese da História de Alguns Conceitos de Homossexual

\begin{tabular}{|c|c|c|c|}
\hline Período & Termo & Significado & Implicações \\
\hline $\begin{array}{l}\text { Grécia } \\
\text { Antiga }\end{array}$ & Pederastia & $\begin{array}{l}\text { Rituais sexuais entre homens de } \\
\text { idades e hierarquias diferentes. }\end{array}$ & $\begin{array}{l}\text { Valorização e incentivo; } \\
\text { enaltecimento do papel da beleza. }\end{array}$ \\
\hline $\begin{array}{l}\text { Grécia } \\
\text { Antiga }\end{array}$ & Philia & $\begin{array}{l}\text { Relação afetiva entre dois homens, } \\
\text { sem intercurso sexual. }\end{array}$ & $\begin{array}{l}\text { Valorização da predileção por } \\
\text { companheiros do mesmo sexo. }\end{array}$ \\
\hline $\begin{array}{l}\text { Início do } \\
\text { século XIX }\end{array}$ & Uranismo & $\begin{array}{l}\text { Mulher no corpo de homem. } \\
\text { Essência do indivíduo. }\end{array}$ & $\begin{array}{l}\text { Luta por direitos sociais pautada na } \\
\text { base biológica desta característica. }\end{array}$ \\
\hline $\begin{array}{l}\text { Segunda } \\
\text { metade do } \\
\text { século XIX }\end{array}$ & Homossexual & $\begin{array}{l}\text { Indivíduos biologicamente atraídos } \\
\text { por pessoas do mesmo sexo. }\end{array}$ & $\begin{array}{l}\text { Intervenções científicas de conversão } \\
\text { e "normalização" da prática sexual. }\end{array}$ \\
\hline $\begin{array}{l}\text { Começo do } \\
\text { século XX }\end{array}$ & Homossexualismo & $\begin{array}{l}\text { Sentido de doença, com a } \\
\text { "efeminação" como sintoma. }\end{array}$ & $\begin{array}{c}\text { Tentativa de descrição e categorização } \\
\text { pormenorizada, para futura } \\
\text { "prevenção" e "cura". }\end{array}$ \\
\hline $\begin{array}{l}\text { Segunda } \\
\text { metade do } \\
\text { século XX }\end{array}$ & Homossexualidade & $\begin{array}{l}\text { Modo de ser do indivíduo. Ênfase } \\
\text { em aspectos psíquicos e afetivos. }\end{array}$ & $\begin{array}{l}\text { Defesa dos direitos homossexuais, } \\
\text { condenação da homofobia. }\end{array}$ \\
\hline $\begin{array}{l}\text { Final do } \\
\text { século XX }\end{array}$ & $\begin{array}{l}\text { Homossexualidades, } \\
\text { homoerotismo, } \\
\text { sub-divisões culturais. }\end{array}$ & $\begin{array}{c}\text { Perspectiva de pluralidade } \\
\text { do fenômeno como composto } \\
\text { por características inter-relacionadas. }\end{array}$ & $\begin{array}{l}\text { Análises culturais; luta por direitos } \\
\text { sociais; defesa do prazer e } \\
\text { da liberdade de conduta sexual. }\end{array}$ \\
\hline $\begin{array}{l}\text { Início do } \\
\text { século XXI }\end{array}$ & $\begin{array}{l}\text { Abandono } \\
\text { de termos fixos; } \\
\text { Homoafetividade. }\end{array}$ & $\begin{array}{l}\text { Retirada do sentido estritamente físico. } \\
\text { Ênfase nos sentimentos e na possibili- } \\
\text { dade de alternância dos mesmos. }\end{array}$ & $\begin{array}{l}\text { Luta cívica por legislação específica } \\
\text { e pela prática sexual sem rótulos. }\end{array}$ \\
\hline
\end{tabular}


Pode-se supor que da mesma forma que o contexto sócio-político se reflete na terminologia utilizada, também poderia afetar as próprias metodologias adotadas na pesquisa. Na segunda metade do século XX, a partir do fortalecimento de pesquisas pautadas na imutabilidade da orientação sexual, cujos dados eram utilizados em defesa dos direitos de indivíduos homossexuais, houve a predominância da concepção de que se a prática não poderia ser modificada ela também não poderia ser condenada. Como evidência disto, pode-se perceber na Tabela 2 a predominância de linhas de pesquisa que enfatizam a determinação biológica, em geral apontando para a ausência de dados relativos ao papel do ambiente neste processo (ver Hamer, Hu, Magnuson, $\mathrm{Hu}$, \& Pattatucci, 1993; Marmor, 1967 e Meyer-Bahlburg, 1977). Além disso, pode-se observar a intensificação do debate sobre a jus- tificativa evolutiva da homossexualidade, partindo do pressuposto de que esta seria geneticamente transmitida para a prole (como, por exemplo, Van Wyk \& Geist, 1984). Concomitantemente, observa-se a escassez de pesquisas relativas ao papel de eventos ambientais, em parte pelo fracasso em sustentar empiricamente teorias defendidas no passado (como a freudiana, como afirmam Bailey \& Pillard, 1991) e em parte pela associação comumente feita entre determinação ambiental e escolha ou, ainda, de que a determinação ambiental implicaria em facilidade de modificação (ver Schüklenk \& Ristow, 1996). A investigação da determinação ambiental passa a ser vista, em geral, como argumento para a condenação e modificação da conduta, sendo assim, mal vista tanto no meio acadêmico quanto pelos movimentos organizados a favor de direitos civis de indivíduos homossexuais (ver Mallot \& Suarez, 2004).

Tabela 2

Datas Iniciais e Finais de Publicações das Áreas e Linhas de Pesquisa Relatadas neste Trabalho

\begin{tabular}{cccc}
\hline Área de pesquisa & Linha de pesquisa & Início & Fim \\
\hline Efeitos ambientais & Estudo de gêmeos & 1960 & 1971 \\
Hormonais & Índice de androgenia & 1959 & 1972 \\
Hormonais & Medidas hormonais & 1968 & 1984 \\
Efeitos ambientais & Padrão exclusivo & 1948 & 1988 \\
Efeitos ambientais & Modificação do comportamento & 1973 & 1994 \\
Efeitos ambientais & Comparações transculturais & 1983 & 1995 \\
Hormonais & Lateralidade & 1965 & 1998 \\
Genética & Genética familiar & 1952 & 2000 \\
Efeitos ambientais & Eventos determinantes & 1979 & 2001 \\
Modelos animais & Modelos Animais & 1947 & 2002 \\
Hormonais & Ordem de nascimento & 1996 & 2002 \\
Hormonais & Habilidades & 1998 & 2002 \\
Hormonais & Medidas corporais & 1981 & 2003 \\
Funcionamento Neural & Funcionamento neural & 1990 & 2003 \\
Efeitos ambientais & Modelos de formação de identidade & 1984 & 2004 \\
\hline
\end{tabular}

Como visto na Tabela 2, os métodos de pesquisa utilizados variaram ao longo do tempo como um reflexo, entre outros fatores, do contexto sócio-político em que tais pesquisas estavam inseridas. Deste modo, o crescimento ou decréscimo na investigação de determinadas variáveis pode ser relacionado às implicações políticas que eram percebidas como derivadas das mesmas. 
Pode-se perceber, por exemplo, que pesquisas de manipulações hormonais e de modificação do comportamento tenderam a ser descartadas em meados da década de 80. Esta mudança de ênfase em pesquisas é compatível com a solidificação da postura da condenação da homofobia e do preconceito relativo à orientação sexual, já que tais pesquisas utilizavam a possibilidade e a pertinência de eliminação da orientação homossexual como justificativas principais (a chamada "busca da cura"). Assim, a alteração na concepção do fenômeno repercutiu, inclusive, na proibição de realização destas pelos órgãos responsáveis - como, nacionalmente, o Conselho Federal de Psicologia (1999) e, internacionalmente, a Organização Mundial de Saúde (Trevisan, 1986/2002).

Não se pretende com esta discussão invalidar as pesquisas relatadas condenando-as integralmente por apresentarem vieses políticos e/ ou culturais. O objetivo é apenas ressaltar esta influência e a importância da identificação destes fatores sociais no desenvolvimento de propostas explicativas científicas.

Alguns exemplos desta influência podem ser destacados. Coopen (1959) teve como objetivo identificar a existência de anormalidades físicas que correspondessem à anormalidade sexual que seria a homossexualidade (como era vista na época). Desta forma, o autor apresenta uma justificativa de sua pesquisa a partir dos dados de outras pesquisas que relacionam patologias a alterações hormonais. Com isto, Coopen (1959) procura justificar a pertinência da hipótese de que o homossexualismo teria base hormonal, pois seria outra "patologia sexual", logo de etiologia similar a outras previamente estudadas.

Apresentando uma perspectiva similar, na introdução de um livro sobre biologia e sociologia da homossexualidade, Marmor (1967) afirma que "a maioria dos psicanalistas representados neste volume . . . opinam que a homossexualidade é decididamente uma doença a ser tratada e curada" (p. 28, tradução nossa). Contudo, a autora considera a possibilidade desta postura ser decorrente do fato da amostragem feita por psicanalistas consistir em pacientes que buscaram tratamento por diversos problemas. Ainda as- sim, a autora é favorável à conversão de adultos e à adoção de medidas de prevenção da homossexualidade para adolescentes, como forma de favorecer a adaptação na sociedade. Contudo, os autores então representados não consideram que a infelicidade ou a inadaptação possam ser reflexos do próprio enfrentamento dos preconceitos presentes na sociedade, e não efeitos endógenos da homossexualidade.

O contexto sócio-político que vigorou praticamente em todo o século XX foi permeado por concepções de que o comportamento homossexual seria o sintoma de uma doença. Enquanto esta perspectiva pode ser lida explicitamente nos artigos supracitados, Meyer-Bahlburg (1977) ressalta que certas decisões metodológicas dos pesquisadores podem ser compreendidas como um reflexo deste cenário maior. Por exemplo, em muitas pesquisas os critérios de classificação de sujeitos homossexuais são mais rígidos e detalhados, utilizando instrumentos e medidas específicas, enquanto que os heterossexuais são classificados pelo pesquisador sem o mesmo rigor.

As diferenças no tratamento dos grupos de participantes talvez sejam o aspecto metodológico no qual a visão do indivíduo homossexual mais influencie. Van Wyk e Geist (1984) exigem a presença de orgasmo em uma relação entre dois homens para classifica-la como homossexual - apesar de não explicarem como seria classificada a mesma relação na ausência de orgasmo - enquanto a mesma exigência não é feita para classificar uma relação heterossexual. Por sua vez, Swaab e Hofman (1990) procuraram isolar a variável "ser soropositivo" trabalhando com dois grupos soropositivos: um homossexual e outro heterossexual. Contudo, ao descreverem as amostras, há uma preocupação dos autores em explicitar de que forma os heterossexuais foram contaminados. A ausência desta mesma preocupação com a amostra homossexual mostra a visão de que um homossexual soropositivo necessariamente haveria se contaminado em relações sexuais, enquanto um heterossexual soropositivo não.

$\mathrm{Na}$ revisão de pesquisas hormonais feita por Meyer-Bahlburg (1977), observa-se também esse viés no tratamento de grupos. Em 57\% das 
pesquisas a seleção de participantes do grupo homossexual ocorreu em hospitais (psiquiátricos ou não) e presídios, enquanto que a amostragem de heterossexuais era, predominantemente, de universitários.

Outra diferença é quantitativa. Em geral os grupos de heterossexuais é muito maior que o de homossexuais, especialmente em pesquisas de medidas hormonais, havendo uma mudança a partir do ano 2000, com uma tendência a equiparar as amostras ou, inversamente, apresentar amostras superiores no grupo homossexual. Esta diferença quantitativa é relevante, pois os dados obtidos são correlacionais, assim, a ausência de nivelamento de amostras pode gerar correlações inverídicas. Uma comparação das pesquisas de maior diferença de amostragem é apresentada na Tabela 3.

Tabela 3

Diferença Quantitativa entre Amostras de Indivíduos Homossexuais e Heterossexuais em Pesquisas Hormonais

\begin{tabular}{cccc}
\hline Autores & $\begin{array}{c}\text { Número de Indivíduos } \\
\text { Homossexuais }\end{array}$ & $\begin{array}{c}\text { Número de Indivíduos } \\
\text { Heterossexuais }\end{array}$ & $\begin{array}{c}\text { Percentual } \\
\text { de diferença }\end{array}$ \\
\hline Bogaert (2003) & 686 & 337 & $49 \%$ \\
Williams et al. (2000) & 424 & 320 & $75 \%$ \\
Cohen (2002) & 42 & 32 & $76 \%$ \\
Blanchard \& Bogaert (1996) & 302 & 434 & $143 \%$ \\
Coopen (1959) & 31 & 53 & $170 \%$ \\
Evans (1972) & 44 & 111 & $252 \%$ \\
Bogaert (1998) & 229 & 594 & $259 \%$ \\
Bogaert \& Hershberger (1999) & 938 & 4187 & $446 \%$ \\
Blanchard \& Ellis (2001) & 260 & 2969 & $1142 \%$ \\
\hline
\end{tabular}

${ }^{a} \mathrm{O}$ percentual de diferença foi calculado tendo por base o número de indivíduos homossexuais como equivalente a $100 \%$.

O número reduzido de participantes no grupo homossexual pode ser interpretado como um reflexo da dificuldade de localizar e identificar indivíduos homossexuais, o que seria compatível com o aumento posterior de tais participantes (podendo estar relacionado à maior exposição e organização de homossexuais enquanto grupo social - ver Trevisan, 1986/2002). Contudo, pode também refletir a visão de que não haveria diversidade no grupo homossexual, de modo a não requerer a investigação utilizando grupos maiores; essa hipótese é compatível com a ausência de detalhamentos na caracterização das amostras, indicando que a classificação "homossexual" seria o único aspecto a ser identificado.

Várias pesquisas em que detalhamentos da amostra homossexual não são apresentados (enquanto que os da amostra heterossexual são) podem ser encontradas na revisão feita por Meyer-Bahlburg (1984), como, por exemplo, a análise das interferências hormonais resultantes de variações no ciclo menstrual ou de distúrbios hormonais. Kolodny, Masters, Hendry e Toro (1971), por sua vez, discutem que a presença de usuários de maconha entre os participantes da pesquisa pode ter afetado os resultados, contudo, tal influência ocorreria apenas na amostra homossexual (amostra na qual se encontravam os usuários) enviesando os resultados. Pode-se perguntar por que os autores não acharam pertinente e/ou viável isolar esta variável se eles reconheciam sua possível interferência nos resultados.

Contudo, a influência de concepções prévias dos autores não afeta apenas a metodologia, mas também a forma de analisar os resultados. Por exemplo, Whitam, Diamond e Martin (1993) observaram a maior incidência de relatos de abusos sexuais na infância de homossexuais como evidência de que a orientação sexual já estaria determinada, de modo a propiciar a exposição destas crianças a contextos de vulnerabilidade sexual. 
O mesmo dado, contudo, poderia ser analisado como evidência ambiental sobre o papel do abuso sexual sobre a orientação sexual indefinida de crianças - isto é, pode-se considerar a possibilidade de que o abuso sexual possa afetar o processo de desenvolvimento da orientação sexual da criança. Aqui o objetivo não é defender uma ou outra hipótese, mas mostrar como certos pressupostos e preconceitos dos autores acabam por direcionar a discussão dos resultados, restringindo as opções de análise, colocando sob suspeita a generalidade e a confiabilidade das próprias conclusões.

O efeito de aspectos sócio-políticos sobre os resultados de pesquisas sobre homossexualidade foi discutido ainda por de Cecco e Parker (1995), que ressaltaram "o perigo de ter a busca por fatos científicos comprometida pela ideologia política dos pesquisadores" (p. 24, tradução nossa). Por outro lado, é importante observar que a maioria dos autores busca destacar os limites dos resultados de sua pesquisa (como os próprios Byne \& Parsons, 1993 e LeVay, 1991; bem como Hamer et al., 1993 e Savic, Berglund, \& Lindström, 2005), mas ainda há uma deturpação da aplicabilidade dos mesmos ao serem divulgados.

Rushton (2001) afirma que, por razões políticas, alguns dados não são debatidos como deveriam, de forma contraproducente para o conhecimento científico. Afirma, ainda, que quando estão envolvidas consequências práticas na descoberta de contribuições genéticas para determinados comportamentos (ou na ausência das mesmas), os dados não são divulgados de forma objetiva, mas segundo interesses político-econômicos relacionados.

Um exemplo claro dos problemas de divulgação dos resultados pode ser observado em Savic et al. (2005). Além do objetivo da pesquisa não ter sido identificar determinantes da orientação sexual e sim discutir a existência ou não de feromônios na espécie humana, os autores ressaltam que seus dados não são indicativos destes determinantes, mas sim de que a orientação sexual estaria relacionada ao funcionamento de estruturas cerebrais - relação esta que os autores afirmam poder ser consequência da prática sexual. Contudo, quando publicada na revista "Veja",
Zakabi (2005) apresenta a pesquisa como mais uma evidência da origem biológica da homossexualidade e a relaciona a outras pesquisas de grande repercussão, como a de LeVay (1991), sem apresentar nenhuma das considerações críticas a tais pesquisas, reiteradamente publicadas no meio científico.

Apesar dos dados científicos serem passíveis de interpretação segundo os interesses de cada grupo social, cuidados relativos ao modo de apresentar e discutir os resultados (evitando posições definitivas e selecionando os veículos de comunicação apropriados) podem reduzir o mau uso do conhecimento científico. Ainda assim, Burr (1998) descreve que o impacto de determinados resultados pode ser tão grande que, mesmo a notícia sendo veiculada com ponderação em periódicos científicos, poderia haver o uso deturpado dos resultados para argumentações políticas e sociais. Tanto McGuire (1995) quanto Weinrich (1995) discutem que tais derivações dos resultados de pesquisas científicas são tão prejudiciais quanto inevitáveis, já que grande parte da divulgação dos resultados ocorre através da mídia jornalística. Considerando que este veículo de informação é controlado por fatores como audiência ou financiamento de grupos políticos com interesses específicos, pode-se considerar que a preocupação dos autores é pertinente.

Stein (1994) afirma que o apelo sensacionalista acaba por supersimplificar os resultados e ignorar as críticas e ponderações metodológicas sobre os mesmos, de modo que os meios de comunicação acabam omitindo as ressalvas da própria comunidade científica e se isentando da discussão a respeito das possíveis influências do contexto histórico sobre as pesquisas relatadas. Assim, por mais que os próprios cientistas relativizem seus dados, a maioria da população acaba por ter acesso a uma interpretação simplista e determinista. Quanto a isso, Hamer e Copeland (1996) afirmam que seria responsabilidade do autor procurar apresentar os resultados de sua pesquisa da forma mais ética possível, bem como procurar contribuir para que a divulgação dos mesmos pela mídia seja cuidadosa. Todavia, pode-se questionar a pertinência desta coloca- 
ção, já que a divulgação de resultados científicos pela mídia pode ocorrer de diversas formas e através de múltiplos veículos de comunicação, o que torna impraticável tal fiscalização e/ou controle por parte da comunidade científica.

Pode-se perceber, portanto, que a análise de um problema de pesquisa não pode ser feita desvinculada do contexto em que a mesma ocorreu, pois este acaba por influenciar o desenvolvimento de linhas de pesquisa quanto à terminologia utilizada, aos objetivos, às metodologias e à análise dos resultados.

Na primeira parte desse ensaio, descreveu-se como certos aspectos sócio-políticos poderiam afetam o desenvolvimento científico. $\mathrm{Na}$ segunda parte, propõe-se a discussão no sentido inverso: como o desenvolvimento científico pode influenciar mudanças sócio-políticas.

\section{Influências Científicas no Debate sobre Direitos Civis de Homossexuais}

Da mesma forma que fatores externos à pesquisa em si podem afetar o modo como a mesma é delineada, os resultados obtidos podem ser interpretados e utilizados de formas variadas fora do contexto científico. O uso de pesquisas científicas para respaldar mecanismos de poder com função social de fiscalização, regulamentação e censura do comportamento sexual humano já é denunciado desde Foucault (1976/2006). Assim, é importante avaliar de que forma as pesquisas sobre os determinantes da orientação sexual podem ser utilizadas no debate sobre direitos civis de homossexuais.

A própria manutenção de uma visão dicotômica da determinação do comportamento, a partir dos extremos "inato" e "aprendido", parece atender a interesses sócio-políticos. Pode-se perceber uma cisão social que utiliza como fundamento para o argumento favorável ou contrário à aquisição de direitos civis por homossexuais, a hipótese da homossexualidade ser um padrão geneticamente ou culturalmente determinado.

Apesar de diversos autores destacarem as implicações políticas de pesquisas sobre determinantes da orientação sexual, tanto Schüklenk e Ristow (1996) quanto Stein (1994), consideram nula a contribuição que estas pesquisas podem fornecer à luta por direitos civis de homossexuais.

Stein (1994) afirma que a mesma informação científica pode ser interpretada como favorável ou contrária aos direitos civis, logo, não se sustentaria como uma fonte definitiva e auto-evidente. Assim, para Stein (1994) o uso político destes resultados é reflexo da concepção do autor que o apresenta e não uma consequência inerente ao dado em si. Para este autor, caso a determinação biológica fosse comprovada, grupos de apoio ao movimento homossexual iriam reivindicar a consideração dos homossexuais enquanto um grupo protegido por lei, embasados na proposta de que não é uma questão de escolha e de que, se é biológica, logo a orientação homossexual seria natural (movimento que tem sido observado atualmente).

Frente a estas argumentações, Stein (1994) afirma ainda que a determinação biológica não seria um argumento definitivo quanto ao debate acerca da escolha. Um exemplo apresentado por Stein (1994) é o exército norte-americano que então aceitava indivíduos de orientação homossexual, desde que estes assumissem o compromisso da abstinência. Essa normativa vigorou até 20 de setembro de 2001, após certificação feita pelo então presidente Barack Obama autorizando a permanência de homossexuais, publicamente assumidos, nas forças armadas (Estados Unidos da América, 2011). A manutenção da política conhecida como "Don't ask, don't tell" era pautada na defesa de que, mesmo que a orientação sexual não fosse uma "questão de opção", a prática sexual seria uma "escolha", permanecendo assim a ocorrência de preconceito ante a prática homossexual.

Por outro lado, Stein (1994) rejeita a prática de condenar a homossexualidade sob argumentação de que essa prática não seria natural por ter sido "artificialmente" criada a partir da cultura humana, já que muitos outros padrões comportamentais também são produto da cultura e nem por isso são considerados uma opção individual.

Além dos argumentos aqui sintetizados, Stein (1994) afirma que vincular as conquistas 
de direitos civis aos achados científicos pode ser problemático. Além de que os mesmos resultados podem fundamentar argumentos favoráveis ou contrários a estes direitos, as pesquisas científicas passam por fases diferenciadas, gerando dados por vezes contraditórios. Assim, a luta por direitos pode ser abalada e se tornar instável. De um modo geral, Stein (1994) defende a continuidade das pesquisas sobre determinantes comportamentais e da luta por direitos civis - mas que sejam independentes uma da outra.

De modo similar, Horgan (1993) critica a investigação de determinantes genéticos do comportamento de modo geral, afirmando que independentemente dos resultados obtidos, tais pesquisas teriam pouco a contribuir. Os seus resultados seriam, para ele, mais utilizados para respaldar preconceitos e medidas drásticas (como aborto em caso de fetos "potencialmente" portadores de algum padrão indesejado).
Esta afirmação de Horgan (1993) provoca a reflexão de que uma explicação genética da orientação sexual, o que tem sido buscado e alardeado por grupos organizados que lutam pelos direitos civis de homossexuais (Mallot \& Suarez, 2004), pode ser utilizada socialmente com o objetivo de eliminação desse padrão comportamental na espécie humana.

Weinrich (1995) afirma que o estudo de determinantes do comportamento envolveria uma discussão valorativa, isto devido à visão tradicional de que a identificação de uma origem genética ou ambiental para um dado padrão estaria relacionada com uma avaliação positiva ou negativa do mesmo. Por outro lado, para McGuire (1995), tanto a hipótese de determinação genética quanto a de ambiental podem ser utilizadas como argumentos em defesa ou contrários aos direitos de homossexuais - ver Tabela 4.

Tabela 4

Possíveis Argumentações Sócio-Políticas Derivadas de Evidências a Favor de Determinantes Biológicos ou Ambientais do Comportamento Homossexual

\begin{tabular}{|c|c|c|}
\hline Determinantes & Favoráveis aos direitos sociais & Desfavoráveis aos direitos sociais \\
\hline Biológicos & $\begin{array}{l}\text { Seria um fenômeno natural e imutável, } \\
\text { impassível de condenações e tentativas } \\
\text { de conversão. }\end{array}$ & $\begin{array}{l}\text { Seria uma condição patológica } \\
\text { a ser prevenida, manipulada } \\
\text { ou extirpada quando possível. }\end{array}$ \\
\hline Sociais & $\begin{array}{l}\text { Seria uma prática cultural, } \\
\text { sem requerer intervenções } \\
\text { médico-terapêuticas. }\end{array}$ & $\begin{array}{c}\text { Seria uma escolha relacionada } \\
\text { a um desvio de caráter, devendo } \\
\text { ser alterada e adequada à sociedade. }\end{array}$ \\
\hline
\end{tabular}

A origem genética pode ser interpretada tanto como evidência de que aquele padrão se constitui como uma doença, quanto pode ser usada na argumentação de que seria um padrão natural à espécie, não devendo ser rejeitado socialmente (ver também Hamer \& Copeland, 1996). A origem ambiental, por sua vez, pode ser interpretada como uma escolha, fortalecendo padrões preconceituosos que alegam ser um "desvio de caráter", ou como evidência do papel cultural, negando a condição patológica.

A vinculação entre a produção de conhecimento científico e a conquista de direitos civis por homossexuais torna-se, assim, vazia (por mais que seja recorrente, como pode ser visto em http://www.apa.org/about/offices/ogc/amicus/ windsor-us.pdf). Argumentos pautados na expectativa de que seja encontrada uma determinação única da orientação sexual tem se mostrado cada vez menos fundamentados cientificamente, em função da necessidade de uma perspectiva interacionista que inclua elementos biológicos e ambientais como relacionados e mutuamente influentes (Poiani, 2010). Além disso, pelo exercício reflexivo aqui apresentado quanto aos possíveis usos políticos de achados científicos, 
pode-se perceber que uma mesma evidência pode ser interpretada e, consequentemente utilizada, para defender posicionamentos políticos antagônicos.

Há que se considerar também que o paralelo usualmente estabelecido entre determinação ambiental e liberdade seria errôneo (Ruse, 1984). Considerar que as influências ambientais sobre padrões comportamentais possam ser concebidas como uma escolha no sentido de uma decisão inteiramente livre de qualquer influência externa é uma perspectiva simplista e discutível (Baum, 1999; Skinner, 1971).

Ainda assim, a própria noção de "escolha" pode receber valoração social diferenciada. Quando aplicada ao padrão homossexual, a possibilidade de "escolha" é interpretada como evidência de que este seria um comportamento amoral, o qual seria passível de ser evitado (Gottschalk, 2003; Ruse, 1984). Já quando a liberdade de "escolha" da orientação sexual é relacionada à heterossexualidade, esta é associada à moralidade (Ruse, 1984). Por outro lado, explicações pautadas na origem genética da orientação sexual teriam por base uma perspectiva de que este seria inevitável, incontrolável, devendo, portanto, ser "aceito" ou "tolerado" socialmente (de Cecco \& Parker, 1995).

Essa atribuição contraditória a duas expressões de um mesmo padrão comportamental, o sexual, reflete concepções de cunho ético, colocando a heterossexualidade em um patamar mais humano, superior, enquanto a homossexualidade estaria associada aos demais comportamentos biologicamente determinados predominantes nas demais espécies (Ruse, 1984). Apesar do posicionamento deste autor ser polêmico, Ruse (1984) aponta para aspectos pertinentes e relevantes em dois sentidos: (a) A noção de liberdade é em si problemática e, mais grave ainda, equivocadamente associada a uma superioridade dentro da espécie; (b) Conceber a origem da orientação sexual como sendo distinta entre homossexualidade e heterossexualidade, reflete uma postura preconceituosa, já que ambas são categorias de um único fenômeno, logo, não haveria justificativa para explicações diferenciadas por princípio.
Desta maneira, pode-se perceber que da mesma forma que questões políticas afetam o desenvolvimento da pesquisa, questões políticas são muitas vezes pautadas no conhecimento científico. É preciso atentar para estas questões de modo a evitar que a política, a religião e/ou a moralidade acabem por funcionar como empecilhos para o pleno desenvolvimento científico na área.

\section{Considerações Finais}

A orientação sexual humana é um fenômeno complexo, tipicamente interdisciplinar, envolvendo um grande número de áreas científicas distintas (das ciências biológicas às ciências sociais), cada uma com seus métodos, critérios de investigação e objetivos, o que dificulta ainda mais o seu estudo. No que se refere mais especificamente à discussão acerca dos seus determinantes, a orientação sexual humana acaba por envolver outros aspectos para além do campo meramente científico ou acadêmico. Isto porque, na cultura ocidental atual, este debate está associado a questões sócio-políticas, como a discussão de direitos civis e o preconceito social (homofobia). A confluência de diferentes perspectivas e interesses na análise de um único tema acaba por ocasionar a ocorrência de falhas metodológicas, teóricas e éticas.

A própria pergunta sobre os determinantes da homossexualidade já traz em si concepções não consensuais - como já discutido. Isto porque pressupõe que a prática sexual "normal" seria direcionada única e exclusivamente ao sexo oposto. Contudo, pode-se discutir pelo que se observa especialmente nas discussões evolutivas que a prática sexual (sem alterações comportamentais relacionadas ao papel sexual e a padrões típicos de gênero) não seria restrita a um sexo específico (ver, por exemplo, a revisão apresentada em Menezes, 2005). É importante considerar que a plasticidade do repertório sexual seja maior do que costuma ser defendido - o que é respaldado pelas hipóteses de que o sexo teria outras funções evolutivas que não apenas a reprodução (Diamond, 1999; Fisher, 1995; Wright, 1996).

Determinantes da homossexualidade têm sido investigados dentro de um contexto sócio- 
-político do qual tais pesquisas não podem ser desvinculadas, de modo que é da mesma sociedade da qual emergem perspectivas tidas como "revolucionárias" que surgem também posturas consideradas "repressivas" - descrevendo a dinâmica histórica já proposta por Foucault (1976/2006).

Para que se possa obter um posicionamento mais confiável sobre esta temática é necessário, assim, realizar novas pesquisas (investigando tanto variáveis já estudadas quanto inéditas) tendo como preceito básico o não-comprometimento prévio com um posicionamento político específico, o que pode ser alcançado a partir de uma postura ética, desde a proposição metodológica até a análise dos resultados. Não se propõe aqui a obtenção de uma "neutralidade" científica, já que esta seria inatingível (Dennett, 1997), mas sim o planejamento metodológico criterioso que possibilite a produção de conhecimento de forma objetiva.

É fundamental, ainda, que se tenha a compreensão de que a construção de conhecimentos científicos acerca da orientação sexual estará sempre permeada por interesses e implicações sócio-políticas que não deveriam influenciar o processo investigativo, mas que não podem ser desconsideradas na compreensão da análise dos resultados. Desta forma, cabe ao cientista discutir sobre os limites e os alcances dos seus achados, contextualizando-os socialmente.

Propõe-se aqui, ainda, que a luta por aquisição de direitos civis não deva ser dependente do avanço científico na identificação de determinantes da orientação sexual, mas, ao contrário, que a compreensão de que o comportamento humano é complexo e multideterminado seja suficiente para o respeito às múltiplas possibilidades de sua manifestação. O conhecimento sobre o comportamento humano que se possui até hoje permite afirmar que o componente genético e o ambiental se complementam de diferentes formas (Lewontin, 2002; Turkheimer, 1998). O respeito à diversidade não deve, assim, ser condicional à ausência de controle que é comumente inferida na determinação genética, mas as próprias noções de direitos, diversidade e controle requerem reflexão por parte da sociedade civil.

\section{Referências}

Bailey, J. M., \& Pillard, R (1991). A genetic study of male sexual orientation. Archives of General, 48, 1089-1096. doi:10.1001/archpsyc. 1991.01810360053008

Bancroft, J. (1994). Homosexual orientation - The search for a biological basis. British Journal of Psychiatry, 164, 437-440. doi:10.1192/ bjp.164.4.437

Baum, W. M. (1999). Compreender o behaviorismo: Ciencia, comportamento e cultura. Porto Alegre, RS: Artmed.

Blanchard, R., \& Bogaert, A. F. (1996). Homosexuality in men and number of older brothers. American Journal of Psychiatry, 153(1), 27-31. doi:10.1176/ajp.153.1.27

Blanchard, R., \& Ellis, L. (2001). Birth weight, sexual orientation and the sex of preceding siblings. Journal of Biosocial Science, 33, 451-467. doi:10.1017/S0021932001004515

Bogaert, A. F. (1998). Birth order and sibling sex ratio in homosexual and heterosexual non-white man. Archives of Sexual Behavior, 27(5), 467473. doi:10.1023/A:1018752513198

Bogaert, A. F. (2003). Interactions of older brothers and sex-typing in the prediction in sexual orientation in men. Archives of Sexual Behavior, 32(2), 129-134. doi:10.1023/A:1022827524721

Bogaert, A. F., \& Hershberger, S. (1999). The relation between sexual orientation and penile size. Archives of Sexual Behavior, 28(3), 213-221. doi:10.1023/A:1018780108597

Burr, C. (1998). Criação em separado: Como a biologia nos faz homo ou hetero. Rio de Janeiro, RJ: Record.

Byne, W., \& Parsons, B. (1993). Human sexual orientation: The biologic theories reappraised. $A r-$ chives of General Psychiatry, 50, 228-237.

Cohen, K. M. (2002). Relationship among childhood sex-atypical behavior, spatial ability, handedness, and sexual orientation in men. Archives of Sexual Behavior, 31(1), 129-143. doi:10.1023/A:1014043504661

Conselho Federal de Psicologia. (1999). Resolução 001/99. Recuperado em http://www.pol.org.br

Conselho Federal de Psicologia. (2013). Declarações de Silas Malafaia. Recuperado em http:// site.cfp.org.br/cfp-se-posiciona-contrariamente-declaracoes-do-pastor-silas-malafaia/ 
Coopen, A. J. (1959). Body-build of male homosexuals. British Medical Journal, 26(5164), 14431445. doi:10.1136/bmj.2.5164.1443

De Cecco, J. P., \& Parker, D. A. (1995). The biology of homosexuality: Sexual orientation or sexual preference? In J. D. de Cecco \& D. A. Parker (Eds.), Sex, cells and same-sex desire: The biology of sexual preference. (pp. 197-213). New York: The Haworth Press.

Dennett, D. C. (1997). Fé na verdade. Disputatio, 3, 3-21.

Diamond, J. (1999). Por quê o sexo é divertido?- $A$ evolução da sexualidade humana. Rio de Janeiro, RJ: Rocco.

Dynes, W. R. (1987). Homosexuality: A research guide. New York: Garland.

Estados Unidos da América. (2011). Certification. Retrieved from http://www.whitehouse.gov/sites/default/files/uploads/dadtcert.pdf

Evans, R. B. (1972). Physical and biochemical characteristics of homosexual men. Journal of Consulting and Clinical Psychology, 39, 140-147. doi:10.1037/h0033203

Ferreira, A. B. H. (2004). Dicionário de língua portuguesa. Recuperado em http://www.uol.com. br/aurelio

Fisher, H. (1995). A anatomia do amor: A história natural da monogamia, do adultério e do divórcio. Rio de Janeiro, RJ: Eureka.

Foucault, M. (2006). História da sexualidade I: A vontade de saber. Rio de Janeiro, RJ: Graal. (Original publicado em 1976)

Gottschalk, L. (2003). Same-sex and childhood gender non-conformity: A spurious connection. Journal of Gender Studies, 12(1), 35-50. doi:10.1080/0958923032000067808

Hamer, D., \& Copeland, P. (1996). The science of desire - The search for the gay gene and the biology of behavior. New York: Touchstone.

Hamer, D. H., Hu, S., Magnuson, V. L., Hu, N., \& Pattatucci, A. M. L. (1993). A linkage between DNA markers on the $\mathrm{X}$ chromosome and male sexual orientation. Science, 261, 321-327.

Horgan, J. (1993, June). Eugenics revisited. Scientific American, 286(6), 122-131. doi:10.1038/scientificamerican0693-122

Kolodny, R. C., Masters, W. H., Hendry, J., \& Toro, G. (1971). Plasma testosterone and semen analysis in male homosexuals. The New
England Journal of Medicine, 18, 1170-1174. doi:10.1056/NEJM197111182852104

LeVay, S (1991). A difference in hypothalamic structure between heterosexual and homosexual men. Science, 253, 1034-1037. doi:10.1126/science. 1887219

LeVay, S. (1996). Queer science: The use and abuse of research into homosexuality. Cambridge, MA: Massachusetts Institute of Technology Press.

Lewontin, R. (2002). Tripla hélice. São Paulo, SP: Companhia das Letras.

Mallot, R. W., \& Suarez, E. A. T. (2004). Principles of behavior. New York: Prentice Hall.

Marmor, J. (1967). Introducción. In J. Marmor, R. H. Denniston, W. H. Perloff, C. M. B. Pare, E. Hooker, M. K. Opler, ...Fisher, S., Biología y sociología de la homosexualidad (pp. 9-42). Buenos Aires, Argentina: Hormé.

McGuire, T. R. (1995). Is homosexuality genetic? A critical review and some suggestions. In J. D. de Cecco \& D. A. Parker (Eds.), Sex, cells and same-sex desire: The biology of sexual preference (pp. 115-145). New York: The Haworth Press.

Mello, M. (Produtora), Amaral, M. H. (Diretora), \& Gabriela, M. (Apresentadora). (2013, 03 fev.). De Frente com Gabi - Silas Malafaia [Programa de televisão]. In SBTonline. Recuperado em http:// www.youtube.com/watch? $\mathrm{v}=\mathrm{WqBtf} 3 \mathrm{ttMug}$

Menezes, A. B. C. (2005). Análise da investigação dos determinantes do comportamento homossexual humano (Dissertação de mestrado, Universidade Federal do Pará, Belém, PA, Brasil).

Meyer-Bahlburg, H. F. L. (1977). Sex hormones and male homosexuality in comparative perspective. Archives of Sexual Behavior, 6(4), 297-325. doi:10.1007/BF01541203

Meyer-Bahlburg, H. F. L. (1984). Psychoendocrine research on sexual orientation: Current status and future options. Progress in Brains Research, 61, 375-398. doi:10.1016/S0079-6123(08)64448-9

Molina, L. P. P. (2011). A homossexualidade e a historiografia e trajetória do movimento homossexual. Antiteses, 4(8), 949-962.

Paul, J. P. (1993). Childhood cross-gender behavior and adult homosexuality: The resurgence of biological models of sexuality. Journal of Homosexuality, 24(3-4), 41-54. doi:10.1300/ J082v24n03_03 
Poiani, A. (2010). Animal homosexuality - A biosocial perspective. Cambridge, UK: Cambridge University Press.

Ruse, M. (1984). Nature/nurture: Reflections on approaches to the study of homosexuality. Journal of Homosexuality, 10(3-4), 141-151. doi:10.1300/J082v10n03 17

Rushton, J. P. (2001). Genes, brain and culture: Returning to a Darwinian evolutionary psychology. Behavior and Philosophy, 29, 95-99.

Savic, I., Berglund, H., \& Lindström, P. (2005). Brain response to putative pheromone in homosexual man. Proceedings of National Academy of Sciences, 102(20), 7356-7361.

Schüklenk, U., \& Ristow, M. (1996). The ethics of research into the cause(s) of homosexuality. Journal of Homosexuality, 31(3), 3-30. doi:10.1300/ J082v31n03 02

Skinner, B. F. (1971). Beyond freedom and dignity. New York: Knopf.

Sociedade Brasileira de Genética. (2013). Manifesto da Sociedade Brasileira de Genética sobre bases genéticas da orientação sexual. Recuperado em http://sbg.org.br/2013/03/manifesto-da-sociedade-brasileira-de-genetica-sobre-bases-geneticas-da-orientacao-sexual/

Stein, E. (1994). The relevance of scientific research about sexual orientation to lesbian and gay rights. In T. F. Murphy (Ed.), Gay ethics: Controversies in outing, civil rights, and sexual science (pp. 269-308). New York: The Haworth Press.

Swaab, D. F., \& Hofman, M. A. (1990). An enlarged suprachiasmatic nucleus in homosexual men. Brain Research, 537, 141-148. doi:10.1016/0006-8993(90)90350-K
Trevisan, J. S. (2002). Devassos no paraíso. Rio de Janeiro, RJ: Record. (Original publicado em 1986)

Turkheimer, E. (1998). Heritability and biological explanation. Psychological Review, 105(4), 782791. doi:10.1037/0033-295X.105.4.782-791

Van Wyk, P. H., \& Geist, C. S. (1984). Psychosocial development of heterosexual, bisexual, and homosexual behavior. Archives of Sexual Behavior, 13(6), 505-544. doi:10.1007/BF01542088

Weinrich, J. (1995). Biological research on sexual orientation: A critique of the critics. In J. D. de Cecco \& D. A. Parker (Eds.), Sex, cells and same-sex desire: The biology of sexual preference (pp. 197-213). New York: The Haworth Press.

Whitam, F. L., Diamond, M., \& Martin, J. (1993). Homosexual orientation in twins: A report on 61 pairs and three triplet sets. Archives of $\mathrm{Se}$ xual Behavior, 22(3), 187-206. doi:10.1007/ BF01541765

Williams, T. J., Pepitone, M. E., Christensen, S. E., Cooke, B. M., Huberman, A. D., Breedlove, N. J., ...Breedlove, S. M. (2000). Finger-length ratios and sexual orientation. Nature, 404, 455456. doi:10.1038/35006555

Wright, R. (1996). O animal moral. Rio de Janeiro, RJ: Campus.

Zakabi, R. (2005, 18 maio). A atração está no cheiro. Veja, 1905.

Recebido: 28/05/2013

$1^{a}$ revisão: 07/07/2014

Aceite final: 30/07/2014 